\title{
A hermenêutica filosófica de Gadamer e sua contribuição para o cenário educacional
}

\author{
José Lucas de Omena Gusmão ${ }^{1}$ \\ Lana Lisiêr de Lima Palmeira ${ }^{2}$ \\ Walter Matias Lima ${ }^{3}$
}

\begin{abstract}
Resumo
O presente artigo visa a analisar as ideias centrais de Gadamer, mais especificamente sua Hermenêutica Filosófica, buscando a articulação desses postulados com a educação. Para tanto, é feito um resgate em torno do surgimento da educação, trabalhando-se, ainda, noções gerais dos primórdios da Filosofia e da chamada Filosofia da educação, enfatizando os principais fundamentos gadamerianos e suas possíveis interligações com o cenário educacional atual, tentando, assim, instigar a reflexão em torno das potencialidades pedagógicas da hermenêutica filosófica na busca de alternativas para alguns problemas visualizados no processo de ensino-aprendizagem contemporâneo.
\end{abstract}

Palavras-chave: Gadamer; Hermenêutica Filosófica; Educação.

\begin{abstract}
The present article aims to analyze the central ideas of Gadamer, more specifically his Philosophical Hermeneutics, seeking the articulation of these postulates with education. In order to do so, there is a redemption around the emergence of education, working also, general notions of the beginnings of Philosophy and the so-called Philosophy of Education, emphasizing the main Gadamerian foundation sand their possible interconnections with the current educational scenario, trying thus instigating reflection on the pedagogical potentialities of Philosophical Hermeneutics in the search for alternatives to some problems visualized in the contemporary teaching-learning process.
\end{abstract}

Keywords: Gadamer; Philosophical Hermeneutics; Education.

\footnotetext{
${ }^{1}$ Graduado em filosofia pela Universidade Federal de Alagoas - UFAL. Mestre em Filosofia pela Universidade Federal de Sergipe - UFS. Doutorando em educação brasileira - UFAL. Professor efetivo do Instituto Federal de Alagoas - IFAL.

${ }^{2}$ Graduada em filosofia pela faculdade Entre Rios do Piauí - FAERPI. Mestra em educação brasileira - UFAL. Doutoranda em educação brasileira - UFAL. Professor Substituta da Universidade Federal de Alagoas - UFAL.

${ }^{3}$ Graduado pela Universidade Federal de Pernambuco - UFPE. Mestre em Filosofia pela Universidade Federal de Pernambuco - UFPE. Doutor pela em Educação pela Universidade Estadual de Campinas - UNICAMP. Professor associado da Universidade Federal de Alagoas, no centro de educação.
} 


\section{Introdução}

A compreensão textual tem sido um desafio para os processos educativos. Diante dos diversos ângulos interpretativos, somos pávidos de nos ensimesmar no problema da legitimidade de nossas práticas pedagógicas, se tais processos passam ou não pelo crivo da validade ou da falsidade. Com isso, somos levados a questionamentos de cunho linguístico e pedagógico, a saber: o que o autor do texto quis expressar com tais palavras? O que determina que a teoria dele seja válida? Qual relação existe entre validade e educação?

Essa circunjacência de problemas foi posta pela tradição epistemológica que remete desde o pensamento cartesiano até os vestígios finais da "Crítica da Razão Pura" do pensamento Kantiano. Entretanto, no limiar do século XX, Hans Georg Gadamer, filósofo alemão, deslindou em suas meditações intelectuais, os caminhos da hermenêutica filosófica. Temos nesse entrecho conceitual, uma guinada sobre o dinamismo da linguagem e das interpretações textuais, e consequentemente, uma reviravolta epistemológica em várias performances das chamadas ciências humanas, que no presente trabalho se direciona ao problema da educação. É sabido pela tradição ocidental que a linguagem, desde o "logos" primordial da antiguidade clássica, surgiu do embate entre linguagem narrativa e linguagem descritiva, tema central da visão tripartida: estoica, alegórica e especulativa.

Num primeiro momento, temos na linguagem narrativa um movimento sócio-religioso, que coloca o poeta como o expoente central das interpretações textuais vindas das epopeias míticas, o poeta na era de ouro dos gregos é o principal educador das crianças. Em seguida, no terceiro período da era filosófica, o período sistemático, promovido por Platão e Aristóteles, temos uma transfiguração diante do "eros pedagógico" do feitio mitológico. 
A alegoria terá seu ápice de fundamentação filosófica no pensamento religioso do início do primeiro milênio da nossa era, pois os contatos da cultura judaico/cristã com o pensamento sistemático da cultura grecoromana exigiam rigor interpretativo e novas modalidade educativas. Essa realidade será transformada no protótipo escolar mais veemente da nossa cultura, a saber: o projeto de educação das crianças promovido pela escola e todas as suas performances tradicionais contempladas até o final do século XX e ainda posta com grande visibilidade nas conjecturas que nos encontramos no início do século XXI. Entretanto, sabemos que essa visão, ao menos na acepção teórica, teve uma transformação atenuante no início da era moderna, em especial com dois movimentos, a revolução científica e a reforma protestante. É o pensamento da reforma que empreende um olhar mais atento para o processo hermenêutico, ainda que tímido e estritamente teológico.

Gadamer, observando o processo histórico e suas insígnias interpretações promovidas por determinados movimentos de estudos bíblicos, viu-se concatenado a impetrar no problema da intepretação e da linguagem, daí se erigiu sua mais célebre obra: "Verdade e Método". Entre as empresas da obra, podemos destacar com importância notória o conceito de "pré-compreensão" do filósofo, pois é na "pré-compreensão" que passamos a compreender o texto que estamos estudando. Daí o autor determinará como devemos proceder para melhor aproveitar o sentido do texto, lembrando que para Gadamer, o texto é consequência de um processo histórico ligado ao dinamismo interpretativo.

Acreditamos que essa proposta promovida pelo horizonte da história em consonância com a Hermenêutica Filosófica de Gadamer seja capaz de elucidar temas reflexivos aos processos educativos, em especial ao ensino infantil, momento crucial da formação humana diante da diversidade textual e interpretativa do próprio mundo.

\section{Principais fundamentos da filosofia gadameriana}


A ideia central do pensamento do filósofo alemão Hans-Georg Gadamer reside em sua Hermenêutica Filosófica, por onde perpassam outros aspectos de grande peculiaridade dos seus estudos e escritos, conforme se tentará expor ainda que de maneira sintética, mas sem deixar de visitar os pontos mais relevantes desenvolvidos por esse filósofo, cuja contribuição de seus trabalhos vai para além da Filosofia, alcançando universos como, por exemplo, o da linguística e o da educação.

Antes de falar a respeito da Hermenêutica Filosófica, impõe-se registrar que, apesar de Gadamer ter sido aluno de Heidegger, buscando nele algumas de suas linhas diretivas, a passagem da Hermenêutica de um para outro não se dá de maneira imediata, já que, enquanto Heidegger se baseava com maior densidade na Hermenêutica da existência, Gadamer vai ter como foco de observação, como muito bem ensina Grondin, "a valorização mais positiva do círculo hermenêutico à problemática de uma hermenêutica das ciências humanas" (2012, p.62).

Dentro dessa concepção e ainda seguindo a vertente esboçada por Grondin, fica claro que Gadamer busca "justificar a experiência de verdade das ciências humanas, e do entendimento em geral, partindo da concepção 'participativa' do entendimento. Ela é constitutiva daquilo que ele chama, na primeira linha de sua obra, de "o problema hermenêutico"” (2012, p.63).

Em outras palavras, pode-se afirmar que o pensamento de Gadamer vai buscar complementar a teoria ontológico-existencial de Heidegger, ampliando essa perspectiva por meio da linguística como um caminho fulcral em busca da compreensão.

Por outro lado, não se pode deslembrar da importância do diálogo para toda interação construtiva que se espera atingir, já que nessa interação dialógica, ou, como declina Gadamer, no diálogo Hermenêutico, tem-se uma pretensão de verdade na qual a expressão só terá confirmação ou negação quando recepcionada e confrontada com o outro sujeito da relação, já que o pensar não deve ser algo isolado, mas levado à abertura dos interlocutores, pois só por meio do confronto de ideias teremos a construção de algo substancial, pois “o verdadeiro carisma do diálogo está presente na 
espontaneidade viva do perguntar e do responder, do dizer e do deixar-se dizer" (GADAMER, 2000, p.131).

Ainda nesta perspectiva podemos falar sobre o encontro com a "alteridade do texto", uma vez que a experiência hermenêutica se dá ao longo da interpretação de um texto ou uma cultura, o que acontece por meio do diálogo, iniciando, dessa forma, o processo construtivo de significado.

$\mathrm{O}$ encontro com a alteridade do texto pode ser traduzido como o exercício do confronto de ideias, pensamentos, valores, enfim, com o confronto entre diferentes mundos e modos de vida, em que a compreensão seja o objetivo maior.

Não é excessivo ressaltar que, na hermenêutica filosófica, a interpretação assume o papel de compreensão de uma tradição e, concomitantemente, de autocompreensão do próprio intérprete.

Afinal, como afirma Gadamer:

Só aquele que não ouve ou ouve mal, que permanentemente se escuta a si mesmo, aquele cujo ouvido está, por assim dizer, cheio de alento, que constantemente se infunde a si mesmo ao seguir seus impulsos e interesses, não é capaz de ouvir o outro.[...] Ouvir o outro é a verdadeira e a própria elevação do ser humano à humanidade (2000b, p.138-139).

Importante destacar ainda que, em razão do círculo hermenêutico e da carga histórica existente na compreensão, a tarefa epistemológica da hermenêutica filosófica busca perceber os preconceitos ou opiniões prévias, sendo essa uma tarefa difícil, tendo em vista que "o preconceito próprio só entra realmente em jogo na medida em que já está metido nele. Somente na medida em que se exerce, pode experimentar a pretensão de verdade do outro e oferecer-lhe a possibilidade de que este se exercite por sua vez." (GADAMER, 1999, p.449).

Assim sendo, na atividade interpretativa, compete ao intérprete buscar que o texto fale, lançando mão de argumentos presentes no texto que venham até mesmo a indagar a própria posição dele como intérprete, até 
porque "as posições ou preconceitos em conflito existem dentro do horizonte expandido onde acontece a fusão de horizontes" (SCHMIDT, 2014, p.163).

Nesse sentido, vê-se que Gadamer, em sua experiência hermenêutica, não clarifica por completo como os preconceitos são legítimos dentro da fusão de horizontes. Como muito bem ensina Schmidt:

Ele apenas nos disse que os preconceitos legítimos são baseados nas coisas em si, que a compreensão correta ocorre quando as partes e o todo formam uma unidade de significado, que a distância, temporal ou não, ajudará este processo, e que a compreensão ocorre com a fusão de horizontes. A fusão de horizontes que ocorre na compreensão é na verdade a realização da linguagem (2014, p.165).

\section{1 "Pré-compreensão" em Gadamer}

A obra Verdade e Método de Hans Georg Gadamer (1999) deixa clara as fundamentações técnicas e filosóficas da hermenêutica: “(...) nós interpretamos um texto à luz de nossos preconceitos; e se uma interpretação nossa se choca contra o texto, devemos procurar substituí-la por outra interpretação - mais adequada. A tarefa hermenêutica é uma tarefa possível e infinita"(1999, p. 78).

Dialogando com Heidegger, vê-se que:

O círculo não deve ser degradado a círculo vitiosus e tampouco considerado inconveniente ineliminável. Nele se oculta uma possibilidade positiva do conhecer mais originário, possibilidade que só pode ser captada de modo genuíno se a interpretação compreender que sua função primeira, permanente e última é a de não se deixar nunca impor pré-disponibilidade, pré-vidências e pré-cognição do caso ou das opiniões comuns, mas fazê-las emergir das próprias coisas, garantindo assim a cientificidade do próprio tema" (1986, p.42) 
Gadamer afirma que esta sentença expressa de forma sucinta o círculo hermenêutico e elucida a fundamentação básica dos métodos hermenêuticos, ou seja, uma possibilidade de textos sem sentido nenhum falarem de alguma coisa, o que permite ao filósofo ter uma précompreensão textual baseada em pré-juizos, pressuposições e expectativas preliminares de um determinado texto, sendo assim o interprete analisa o texto com determinadas "pré-compreensões". O trabalho a ser feito sobre determinado texto consiste na revisão contínua e nos resultados prescritos anteriormente. Daí, temos a interpretação como tarefa possível, mas infinita.

O intérprete não se justapõe ao texto como uma espécie de folha em branco, que por meio da experiência iria escrever o conteúdo da página em branco, mas ele se aproxima do texto com suas "pré-compreensões" bem definidas em seus pré-juízos. Está pré-compreensão do intérprete, evidentemente, é consequência do processo cultural de teorias, linguagem, mito, ciências e outras; tais mecanismos da cultura levam o intérprete ao primeiro delineamento do texto, seja esse texto antigo ou atual. Porém, esse esboço inicial do texto pode ter validade ou não, com isso, temos um problema: o que faremos para entender a validade do esboço inicial do texto? Para Gadamer, é justamente a análise póstuma do texto que nos fornecerá a validade do seu esboço inicial, ou seja, se de fato corresponde ao texto. Se a primeira interpretação não tiver validade com o texto, o intérprete desenvolverá um segundo esboço de validade do texto. Como consequência, teremos uma nova interpretação que tenta especular e provar tanto o texto quanto o contex to como sendo ou não adequado. Esse processo de interpretação seria substituído por outro esboço, indo ao infinito.

É evidente que cada interpretação é exercida pelo que se sabe, e o que se sabe é demudado e transformado no curso da história humana; as possibilidades mudam e na medida em que observamos o texto ampliamos o contexto, o conhecimento sobre o homem, sobre a natureza e sobre a linguagem. Com isso teremos releituras dos textos, o que, para Gadamer consiste em "novas hipóteses interpretativas a submeter à prova" (1999, p.81). Comprovamos de fato a tarefa infinita e possível da interpretação.

Filos. e Educ., Campinas, SP, v.10, n.2, p.379-405, maio/ago. 2018 - ISSN 1984-9605 
A mente do intérprete é uma "folha plena" marcada por "précompreensões" e "pré-juizos". Percebemos na leitura de Gadamer que o intérprete está em constante "conflito" com suas prévias do texto e com o próprio texto, diz o filósofo: "seja quando o texto não apresenta sentido algum, seja quando seu sentido contraste irremediavelmente com nossas expectativas" (1999, p.85).

Tais conflitos impulsionam, segundo Gadamer, a hermenêutica a analisar e especular suas "pré-compreensões" e "pré-juízos" e buscar na dinamicidade, interpretações potencialmente mais apropriadas. Alerta o filósofo:

quem procura compreender fica exposto aos erros derivados de pressuposições que não encontram confirmação no objeto". Portanto "A compreensão de tudo o que se deve compreender consiste totalmente na elaboração desse projeto preliminar, que obviamente é revisto continuamente com base no resultado da penetração ulterior do texto" (1999, p. 91).

Com efeito, a gradação do projeto inicial de análise do texto insurreciona a sua alteridade. Descobrimos o que o texto tem a nos falar e, em seguida, chegamos à sua heterogeneidade, que é consequência da nossa mentalidade, e ao distanciamento de nossa cultura em virtude das “atribuições dos sentidos”, que é construído a partir de nossas prévias compreensivas do texto que descartamos sob determinação do próprio texto. Menciona Gadamer:

(...) quem quiser compreender um texto deve estar pronto a deixar que o texto lhe diga algumas coisas. Por isso, uma consciência educada hermeneuticamente deve ser preliminarmente sensível à alteridade do texto. Tal sensibilidade não pressupõe 'neutralidade' objetiva nem um esquecimento de si mesmo, mas implica uma precisa tomada de consciência das próprias pressuposições e dos próprios preconceitos. (1999, p. 91) 
As “pré-compreensões”, "pré-juízos”, “pressuposições” e "preconceitos" do intérprete não devem estabelecer coerção na análise do texto, não devem "calar" o texto. O intérprete precisa ser compassivo à "alteridade do texto" e que o texto jamais seja pretexto para que só o intérprete discorra sobre ele. O intérprete deve expressar o texto para escutálo, para lhe dar sentido a cada análise e, por conseguinte, estabelecer uma aproximação o mais adequada o possível da "alteridade do texto". Trata-se de apresentar o que o texto realmente é.

Com as múltiplas interpretações de textos que perpassaram séculos somos impulsionados a pensar que o autor do texto jamais tivesse em sua mentea condição de ver tais interpretações. As interpretações vão além do que o autor aprecia, deste modo, eram ausentes de validade. Para Gadamer o autor de um texto é um "elemento ocasional", ou seja, o autor não é o produto do texto e como aquele origina o texto e é totalmente livre. $\mathrm{O}$ autor tem efeitos sobre o que vem depois dele na história, mas que são efeitos que o próprio autor não poderia presumir e nem conceber; com isso, tais causalidades do texto entram em ligação com outros alvitres da cultura.

Os efeitos contidos na história de um texto ininterruptamente definem mais inteiramente a sua acepção e sentido. O intérprete também acompanha a leitura na elucidação da história dos efeitos. Um cientista não assimila todas as decorrências da teoria que ele mesmo desenvolveu e criou; não as traz à luz porque não pode enxergá-las. Falta-lhe o saber necessário para elucidá-las. Sendo assim, o cientista não vê, na realidade, o alargamento histórico que sua teoria estabelece. Como hermeneuta, o historiador da ciência enxerga as teorias que o cientista desenvolveu com clareza e evidência que nem o próprio criador da teoria pode apreender. Vale ressaltar que o que foi dito sobre a teoria científica vale para qualquer forma de conhecimento humano expresso nas multiplicidades de textos.

A distância temporal que o intérprete enfrenta não deve ser, em nenhuma condição, empecilho para o entendimento do texto. Salienta Gadamer:

Filos. e Educ., Campinas, SP, v.10, n.2, p.379-405, maio/ago. 2018 - ISSN 1984-9605 
(...) quanto mais nos afastamos cronologicamente do texto, mas deveremos nos aproximar dele como melhor compreensão, posto que aumentem os dados de consciência que nos põem em condição de descartar as interpretações errôneas ou menos adequadas, e substituílas por interpretações novas e mais justas (1999, p. 99).

Segundo Gadamer não se trata da validade da interpretação pela simples razão de ser recente, mas das eliminações dos sustentáculos que tornam válida uma interpretação no intuito de formular e experimentar outra, que possivelmente tenha sido até rejeitada no passado por conta dos valores de sua época ou por interpretações novas e atualizadas.

$\mathrm{Na}$ ótica de Gadamer as "pré-compreensões" não têm sentido desestimado, mas se apresentam como conjunturas, pois aquelas que determinamos hoje como juízos terão possibilidades de serem précompreensões póstumas, e as pré-compreensões poderão ser juízos. Diz Gadamer: "os pré-conceitos do indivíduo são mais constitutivos de sua realidade histórica do que seus juízos" (1999, p. 106).

Em suma, os preconceitos que geram as pré-compreensões dos intérpretes são estabelecidos pela herança contida na tradição. Gadamer observa a tradição no modo romântico feito na autoridade; pensa que a proposta iluminista de querer transpassar todo e qualquer preconceito à luz da razão é uma aspiração coerente, no entanto, tal pretensão não surge necessariamente com a desaprovação contida na não discriminação de todo ou qualquer preconceito e da autoridade da tradição, isso pelo fato de preconceitos evidentes e tradicionais poderem ser adequados e produtivos para o conhecimento. A recusa iluminista da tradição se torna um preconceito não adequado.

Feitas essas considerações preliminares, passar-se-á a voltar o olhar à Filosofia da Educação, até se chegar à importância dos fundamentos teóricos de Gadamer ao campo educacional propriamente dito, conforme se verá adiante. 


\section{2- Um breve retrospecto acerca do surgimento da filosofia e seu enlace com a educação}

Tomamos aqui o surgimento da filosofia dentro de uma proposta que assume o caráter histórico da filosofia como um elemento originário, o que é bem nítido no pensamento de Heidegger quando aponta no início de "Ser e Tempo" que um dos problemas urgentes do pensamento filosófico é o "problema do ser". Esse estado de coisa designa um olhar para o antigo que "ainda fala", o que é bem próprio da hermenêutica filosófica e das condições existenciais do homem perante sua realidade ôntica, uma espécie de "metafísica subjetiva" que se sustenta na temporalidade e espacialidade.

Nesse sentindo, tomamos o discurso narrativo mítico e o discurso descritivo filosófico grego como meios "originários" possíveis para se pensar os processos educativos.

Assim, dentro desse contexto, é fundamental lembrar que tempestades, raios e outros acontecimentos naturais se tornavam, ao mesmo tempo, fatos que além de desconhecidos também eram assustadores, causando sensação de ameaça ao ser humano primitivo.

Com a evolução da humanidade, houve o aperfeiçoamento não só dos modos de enxergar a natureza, bem como de lidar com a mesma, o que fez com que ficassem atrelados aos deuses inúmeros acontecimentos dessa ordem, surgindo assim os primeiros mitos.

Aqui, crucial ressaltar que os mitos já representavam, de certa forma, uma busca dos homens de tentar impor sentido ao mundo que lhes cercava, ou seja, de explicar a origem do universo e de tudo que nele existia.

Todavia, em razão do desenvolvimento das sociedades e a fusão de culturas, passaram-se a conhecer novos mitos e crenças, o que acarretou alguns conflitos, os quais foram determinantes ao surgimento da Filosofia na Grécia Antiga, uma vez que se buscavam respostas calcadas em argumentos lógicos, experimentos e racionalidade.

Dessa forma, paulatinamente, os homens foram conquistando os espaços mundanos, desmistificando cada vez mais a natureza e dando margem à passagem do mito para a razão, eis que não mais sendo os mitos 
capazes de responder satisfatoriamente às indagações que iam tomando conta desse novo cenário, abriu-se espaço ao terreno filosófico como campo fértil para esse novo momento.

Entretanto, imperioso registrar que na Antiguidade não havia uma nítida diferença entre ciência e filosofia. Conforme nos ensina Lindberg:

Não existia nada na Antiguidade correspondendo à ciência moderna como um todo, ou a ramificação da ciência moderna tais como a física, a química, a geologia, a zoologia e a psicologia. Os temas dessas disciplinas pertencem todos à filosofia natural e portanto a um projeto filosófico mais amplo. (1983, p.511).

Dentro dessa linha de raciocínio e após esboçar um breve panorama acerca da transição do mito para a Filosofia, deve-se trazer à cena um conceito de Filosofia, até para didaticamente melhor delimitar o caminho que estamos percorrendo, e para tanto lançamos mão de Abbagnano (2000), quando ele leciona que esta é a posse ou aquisição de um conhecimento que seja, ao mesmo tempo, o mais amplo e o mais válido possível e que deve ser usada em benefício do homem.

Ainda de acordo com Abbagano:

Esses dois elementos recorrem frequentemente nas definições de Filosofia, em épocas diversas e sob diferentes pontos de vistas. São reconhecíveis, por exemplo, na definição de Descartes, segundo a qual esta palavra significa o estudo da sabedoria, e por sabedoria não se entende somente a prudência nas coisas, mas um perfeito conhecimento de todas as coisas que o homem pode conhecer, tanto para a conduta de sua vida tanto para a conservação de sua saúde e a invenção de todas as artes. (2000, p.442).

Cumpre-nos ainda fazer uma correlação mais íntima entre a Filosofia e a Educação. Em outras palavras, tentaremos explicar a Filosofia da Educação como o campo da Filosofia que intenciona amparar teoricamente 
a prática pedagógica de determinado modelo educacional. Em linhas gerais, significa dizer que o filósofo educacional busca justificar a atividade do pedagogo, dando-lhe assim o suporte conceitual dentro dessa vertente.

Não se torna despiciendo assinalar também que a Filosofia divide-se em dois grandes períodos, os quais representam verdadeiros marcos de estudo, quais sejam: período Pré-Socrático (também chamado período da filosofia da natureza) e Período Socrático com olhares mais voltados ao homem propriamente dito.

Logicamente, cada período e as ideias neles propugnadas trarão influências ao contexto educacional. Entretanto, como o objeto central deste trabalho se centra na hermenêutica de Gadamer e sua importância ao campo da educação, procuraremos observar como o dialética, isto é, como a necessidade da linguagem e consequentemente a manifestação do diálogo inauguraram o espaço filosófico.

Desse modo, percebemos que já em alguns pensadores pré-socráticos havia a demonstração do elo entre a linguagem e o discurso filosófico.

Como exemplo, podemos, fazendo um breve resgate, citar Zenão de Eléia, que, em pleno século V a.C, defendia o monismo e o imobilismo do ser, apresentando como característica marcante o paradoxo das discussões que levantavam críticas ao pluralismo. Tais paradoxos vão desaguar em postulados que colocam em questão o senso comum, o que fez com que Zenão, nessa tarefa de refutar as teses de um interlocutor, a partir de princípios admitidos como verdadeiros pelo próprio interlocutor, seja considerado um dos fundadores da dialética.

Nesse contexto, essencial asseverar que os sofistas também merecem ser vistos como figuras de destaques no campo da dialética, já que, por figurarem em um momento em que a arte da argumentação era fundamental, mostravam-se estes como verdadeiros mestres da oratória, fazendo com que a dialética, a linguagem e a poesia ocupassem posições estratégicas e defendendo a ideia de que esses valores deveriam se fazer presentes na educação do homem da infância à idade adulta. 
Já com Sócrates, considerado até a fase atual como um dos mais importantes filósofos de todas as épocas, as premissas predominantes se guiavam pela virtude e pelos princípios morais, sendo ele defensor da ideia de que filosofar sobre a vida é o caminho para a felicidade.

Platão ao narrar as palavras de Socrátes, em sua obra "o Banquete", evidencia que:

Nada mais faço a não ser andar por aí convencendo-vos, jovens e velhos, a não cuidar com tanto afinco do corpo e das riquezas, como de melhorar o mais possível a alma, dizendo-vos que dos haveres não provém a virtude para os homens, mas da virtude provêm os haveres e todos os outros bens particulares e públicos (2004, p.57).

Vê-se que também com Sócrates a linguagem toma uma configuração de grande relevância no discurso filosófico, sendo crucial destacar mais uma vez que o elemento central de suas reflexões não se baseava na natureza, como fizeram os sofistas, mas, no ser humano.

Assim como Sócrates, Platão também utilizava a maiêutica como método filosófico, sendo com ele que os diálogos realmente se tornaram um gênero literário em que a dialética é o escopo maior dessa essência filosófica.

Já com Aristóteles, é no mundo físico que as ideias são lançadas de forma prática, sendo necessário que os homens distingam o prático do teórico por meio de experimentos. Em oposição ao que defendia Platão, Aristóteles enunciava que as ideias não existiam antes das experiências, já que, de acordo com ele, as ideias não preexistiriam a seu objeto.

Como muito bem aduz Reichenbach:

A ciência da lógica foi descoberta pelos gregos. Isto não significa que antes deles não existisse pensamento lógico: de fato, este é tão antigo quanto o pensamento, pois toda imaginação fértil é controlada por regras da lógica.. Uma coisa é aplicar tais regras inconscientemente nas operações do pensamento prático, outra coisa é formulá-las 
explicitamente, de molde a sistematizá-las sob a forma de uma teoria. A Aristóteles cabe o mérito de ter iniciado o estudo orgânico das regras lógicas (1961, p.208)

Com esse breve resgate acerca das origens da Filosofia, consegue-se, de certa forma, depreender como a concepção de ensino foi se formulando no decorrer do tempo, ressaltando-se que, na Grécia antiga, a noção de cuidar se ligava basicamente à educação dos filhos, educação esta que primeiro se fazia presente no seio familiar, para, posteriormente, se buscar desenvolver as potencialidades das crianças, fazendo delas bons cidadãos, cabendo tal tarefa ao Estado.

Os paradigmas da educação surgiram com a Paideia, cuja acepção de origem grega significa "criação de meninos", em que se tem em mente a ideia de que criar remete a cuidar e cuidar é educar para o bem, uma vez que a educação, baseada nos princípios gregos, se pautava na formação do bem e do belo, trazendo uma série de conhecimentos como artes, matemática, música, poesia e política.

De acordo com Jaeger:

Inicia-se no tempo de Sófocles um movimento espiritual de incalculável importância para a posteridade. É a origem da educação no sentido estrito da palavra: a paideia. Foi com os sofistas que essa palavra, que no século IV e durante o helenismo e o Império haveria de ampliar cada vez maisa sua importância e a amplitude do seu significado, pela primeira vez foi referida à mais alta areté humana, $\mathrm{e}$ a partir da "criação dos meninos", acaba por englobar o conjunto de todas as exigências ideais, físicas e espirituais, que formam a kalokagathía, no sentido de uma formação espiritual consciente. No tempo de Sócrates e de Platão, estáperfeitamente estabelecida essa nova e ampla concepção da ideia da educação. (2013, p.335) 
Reforçando o acima citado, Ghiraldelli (2006) diz que foi com a Paideia ${ }^{4}$ que se começou a pensar um sentido mais original em Educação no Ocidente.

Não é excessivo trazer à cena alguns dos ideais de Michel de Montaigne, já que o mesmo apresentou importância indiscutível à Filosofia da Educação, tendo, inclusive, dedicado em sua obra "Ensaios" dois de seus livros à educação.

Assim, apenas para delimitarmos didaticamente e cronologicamente o contexto das ideias apresentadas, necessário se faz um rápido esclarecimento acerca de fase em que se desenvolveu o pensamento de Montaigne dentro da seara histórica-filosófica.

Dessa forma, podemos declinar que tendo Montaigne vivido no século VI, representando o período renascentista, é o mesmo considerado humanista por assumir o ideal de que os homens devem ser educados e respeitados desde a sua infância, dando grande destaque à educação das crianças.

Para Montaigne, a criança deveria ser formada para refletir a si mesma e aí ela estaria apta a compreender o mundo e tudo o que está a sua volta. É nesse processo educacional que a criança, desde cedo, vai aprender a respeitar seu semelhante e se tornar capaz de viver em coletividade, livrando-se das inseguranças e medos impostos pela sociedade.

Dessa forma, com base no acima declinado, pode-se perceber que existe um elo bem forte entre a Filosofia e a Pedagogia, até porque, seja pela análise das correntes pedagógicas liberais ou progressistas, vê-se que os maiores expoentes da Filosofia influenciaram de forma preponderante o processo de ensino-aprendizagem.

\footnotetext{
${ }^{4} \mathrm{~A}$ expressão Paideia é originária do grego, sendo utilizada para exprimir a ideia de educação na sociedade grega clássica. A princípio o termo significava apenas criação dos meninos e à educação familiar, aqui se incluindo os princípios de trato social bem como morais. Com o desenvolvimento da sociedade ateniense, paideia assume a conotação de um processo de educação que visava a contemplar diversos aspectos da vida do homem, abordando campos como gramática, matemática, geografia, retórica, dentre outros.
} 
Cumpre-nos ressaltar que com a afirmação acima não intencionamos tentar sinonimizar Pedagogia e Educação, até porque se trata de universos que, apesar de se entrelaçarem, apresentam diferenças elementares.

De forma superficial, podemos asseverar que a pedagogia é um campo da teoria educacional que orienta as práticas formativas dentro do contexto mais amplo.

Nas palavras de Antoine Prost, na obra Éloge des pédagogues "a pedagogia não é um saber sobre o ensino, mas sobre os estudos; [...] desde a origem ela tem como foco os alunos, em sua relação com o saber: como eles aprendem? Como reconstroem os saberes para si mesmos?” (1982 apud MORANDI, 2008, p.09).

E Morandi prossegue tal raciocínio ao exprimir que a Pedagogia tem como objeto na atualidade "o campo das experiências e dos conhecimentos compartilhados (ou não compartilhados) por professores e alunos sobre a possibilidade de ensinar e aprender [...]" (2008, p.09).

Assim, não seria precipitado sustentar que a Filosofia da Educação é um segmento da Filosofia que busca questionar e refletir a educação sob os seus mais diversos prismas, já que, conforme entendimento de Reboul (1971), a educação permite discernir o sentido humano dos debates filosóficos para além de seus aspectos técnicos, colocar os conceitos mais abstratos à prova da prática, mostrar que a filosofia não é somente trabalho de especialistas, mas dos homens.

\section{A importância dos postulados de gadamer ao contexto educacional}

Conseguir delimitar onde finda a filosofia moderna e se inicia a filosofia contemporânea é algo ainda não unânime entre os estudiosos da área. Todavia, aqui se tomou como parâmetro para estabelecer essa cronologia da filosofia contemporânea a que surge após o idealismo alemão. E, dentro dessa vertente, tem-se a Fenomenologia, a qual pode ser dividida em três linhas: a transcendental (de Husserl), a existencial (de Maurice 
Merleau-Ponty e Jean Paul Sartre) e a hermenêutica (de Hans George Gadamer e Martin Heidegger).

Em razão de o objeto central do presente estudo se voltar a analisar a Filosofia Gadameriana e suas principais influências à educação, dar-se-á destaque à Hermenêutica de Gadamer e às suas implicações no contexto da relação de ensino-aprendizagem, de acordo com o que passará a ser detalhado.

\subsection{Como a Educação e a Hermenêutica Filosófica se} relacionam?

De acordo com o propugnado por Flickinger (2014), a questão em tela põe em relevo a fertilidade da hermenêutica Gadameriana para a atuação da possibilidade de uma pedagogia concreta, fertilidade essa que se mostra, antes de tudo, na recuperação de aspectos omitidos nos debates e práticas pedagógicas hoje em vigor.

Tal raciocínio pode ser resumido em duas questões centrais:linguagem/reflexão e recuperação do diálogo vivo na prática educativa.

Ao trabalhar a primeira questão aqui apresentada, é importante ressaltar que Gadamer vê na linguagem o campo da experiência existencial do homem. E esse pensamento vem realmente acentuar problemas fortes do atual cenário educacional, como a questão das discussões que acompanhamos hoje sobre a crescente carência na formação básica das crianças e dos adolescentes, tais como dificuldade de leitura, de estruturação de argumentos. Tem-se, assim, que a linguagem vem deixando de ser vista como "logos" e sendo transformada em mero instrumento de troca de informações, não fazendo com que a pessoa busque o acesso à riqueza de seus significados contextuais. (2014, p.67).

Além disso e com base no declinado em Flickinger (2014, p.67), sabe-se que o avanço da tecnologia da informação, por já trazer ideias prontas e colocadas facilmente à disposição do leitor, vem reforçando o 
desvirtuamento do papel da língua como espaço de construção e reflexão do sentido. E é contra essa dinâmica que a hermenêutica filosóficase insurge, ao alertar que a pedagogia deve se opor a esse reducionismo e buscar manter viva a função da língua como moradia, que é a forma como Gadamer a compreende.

Ainda segundo a tese gadameriana a língua é o horizonte existencial do ser humano, tomando por linguagem não apenas o dito,mas qualquer modo de manifestação do pensamento, que vai até mesmo do não verbal, ressaltando que a própria construção da personalidade da criança passa necessariamente pela linguagem.

Desse raciocínio, já se pode extrair inicialmente três consequências de âmbito pedagógico. A primeira consequência é a necessidade de usar, o mais cedo possível, a fala racional com a criança, ainda mesmo no estágio em que ela não consegue se expressar verbalmente, para que ela aceite a linguagem como forma do seu estar no mundo. A segunda consequência é a necessidade de responder às repetidas perguntas delas emanadas. Muitas vezes,os insistentes porquês quase que intermináveis se tornam cansativos para os adultos, todavia são essas indagações que fazem com que as crianças aprimorem o senso crítico, fundamental no seu desenvolvimento cognitivo.A terceira consequência é o entrosamento na língua, que exerce papel decisivo da integração que determinada pessoa terá em determinado grupo, ou seja, na linguagem também está em jogo a sociabilidade de uma pessoa. (2014, pp.70-71).

Apenas tentando esclarecer o que se vem discorrendo até o presente momento em relação à valoração da dialética no processo educativo, importante registrar que entendemos o homem como um ser semiótico, um ser dotado de capacidade de comunicação e que para atingir seus anseios sociais necessita fazer uso da linguagem.

Em consonância com o que explicita Oliveira:

Hegel, o grande Aristotélico dos tempos modernos, antecipa, de certo modo, através de sua vinculação a Aristóteles, algumas das intuições fundamentais do pensamento contemporâneo. Seu esforço filosófico 
parte da consideração do homem como ser semiótico: é através da linguagem que se manifesta a natureza do homem como ser lógico. $\mathrm{O}$ homem é, assim, o ser da comunicação e é no âmbito da fala, ou seja, do som dotado de sentido, que o real se lhe manifesta. A linguagem, o logos, nesse sentido, perpassa toda práxis humana, pois o específico do homem é tudo situar na esfera do sentido [...] Na linguagem do homem, portanto, a racionalidade imanente ao real alcança sua articulação. (1993, p. 198)

Assim, o raciocínio sustentado até o presente momento mostra que a tarefa educacional mais estrita, ao compor novas ressignificações para seus entes estruturantes, deve deixar de ser uma atividade que apenas reproduz conteúdos, mas que, acima de tudo, atue com a hermenêutica filosófica, pois busca a possibilidade da compreensão para recriar a educação no decorrer do processo de ensino-aprendizagem, o que já vai remeter à segunda questão a ser analisada que é a necessidade da recuperação do diálogo vivo para a educação.

\subsection{A relevância do diálogo vivo na construção do processo de ensino-aprendizagem}

A tendência atual de fazer prevalecer o resultado perfeito de uma argumentação em detrimento do processo de sua elaboração denota um cientificismo, em que o professor define todos os conceitos, petrificando o diálogo e cortando o acesso à hiponoia ${ }^{5}$ da fala. $\mathrm{O}$ caminho das ciências modernas vai da "palavra ao conceito", enquanto na hiponoia há uma resistência a essa via, que congela os sentidos em um invólucro abstrato.

Mas, pelo que se denota com o estudo em tela o diálogo vivo que mostra interesse pelo âmbito da pedagogia é aquele que assume uma postura que pressupõe o respeito mútuo e a seriedade das ponderações, ou seja, é o

\footnotetext{
5 Sobre a hiponoia, explica Del Pozo (1988, p. 74): "sospecha de que por debajodellenguage, a la sombra de lo que se dice, está el sentido más importante. Lo que losgriegosllamaban "alllegoría” o "hiponoia”. Un sentido menor, más superficial, enmascarando pero a pesar de todo transmitiendootro sentido".
} 
uso de argumentos que permite a aprendizagem por meio da elaboração do novo.

E Gadamer, em seu texto sobre a "Incapacidade para o diálogo"(1972), critica a postura dominadora do professor que, mesmo sustentando um discurso de forma participativa de aprendizagem, trata seus alunos como súditos, buscando dominar a relação, colocando-se em uma posição de vantagem que afasta o mesmo do processo, não dando margem muitas vezes sequer aos questionamentos, já que ele se rotula como detentor absoluto do conhecimento, numa perspectiva que só eleva sua vaidade pessoal e impede a cooperação, residindo aí um dos motivos que dificultam a troca de saberes inter ou multidisciplinares (2014, p.91).

Não é esse o objetivo do processo educativo, devendo o professor assumir o papel de atuar nas lacunas que o discente tem em sua formação, sem deixar de desconsiderar os elementos prévios que ele apresenta como sujeito social e histórico. É essa não-totalidade que vai permitir a interpretação e reinterpretação desses elementos e assegurar a busca de um entendimento em que são possibilitadas novas composições de significados, sendo nesse processo que a educação constitui um novo horizonte de compreensões.

Nesse processo não há mais um professor que professa (ensina) e um aluno que se alumia (aprende), mas, sim, a consciência que só se compreende verdadeiramente interpretando a si e ao seu mundo, podendo, nessa dinâmica, entender melhor os conteúdos do seu mundo para então recriá-los. Há, aqui, de certa forma, uma ruptura com a "pedagogia da aceitação", em que existe uma relação de desigualdade que apenas o educador sabe e tenta fazer com que o educando supere sua "ignorância", incutindo nesses educandos a necessidade de aceitarem a primazia do que lhes é transmitido, limitando seus horizontes e tirando-lhes a possibilidade de serem autônomos, para uma "pedagogia de resistência, em que se aposta na visão do reconhecimento de independência e autonomia do outro segundo o nível e o potencial de atuação de cada um(GADAMER, 2014, pp.104-105). 
É na medida dessa especificidade que educador e educando devem assumir a responsabilidade pelo êxito do processo de formação. Assim, em se tratando de uma responsabilidade compartilhada, nenhum dos participantes estará legitimado a impor, de modo unilateral, suas diretrizes sem antes fundamentá-las e torná-las transparentes. Tal como acontece na estrutura do jogo e do diálogo vivo, educador e educando devem tomar um ao outro como participante indispensável na construção do saber (GADAMER, 2014, p.107).

É necessário que se possibilite o que se chama de "eros pedagógico", em que o aluno tome posição diante do seu outro, trabalhe os sucessos e os conflitos daí originados, sendo essa a característica essencial do processo pedagógico (GADAMER, 2014, p.94).

Apenas em termos de esclarecimento, deve-se ressaltar que ao trazer a expressão "eros pedagógico" deve-se ter em mente que na Paidéia falavase da educação como atividade prazerosa, dedicada aos homens livres e próxima da eudaimonia, expressão grega que se traduz como felicidade ou bem-estar.

Não é demais asseverar que, pela origem etimológica, a palavra escola se relaciona ao lugar do ócio, destacando-se, ainda, que os gregos falavam do encantamento diante do mundo que o conhecimento provocava nas pessoas, encantamento este também chamado de êxtase no ócio.

Assim, com base nas ideias apresentadas, vê-se que a filosofia gadameriana busca a valorização do diálogo na educação visando a recuperar, em especial, esse lado erótico-social do processo de ensinoaprendizagem.

Dessa forma, ter-se-á uma perspectiva universalista da hermenêutica filosófica na prática educativa, pois, como leciona Flickinger(2014) o saber verdadeiro não nasce única e exclusivamente da aplicação de um procedimento metodológico, mas é construído utilizando uma relação de dependência a pressupostos dos quais esse saber precisa não só tomar consciência como reconhecer momentos peculiares de seu processo. E essa abordagem investigativa e interpretativa, cuja valoração tanto se busca e se 
defende, deveu-se à hermenêutica gadameriana, que extraiu daí o que se trabalha no campo filosófico como pretensão universalista. $\mathrm{Na}$ práxis educativa, essa descoberta repudia uma racionalidade instrumental exclusivista, sensibilizando educadores a conscientizarem seus alunos sobre os efeitos perigosos do puro e absoluto cientificismo contemporâneo.

Afinal, como muito bem enunciava Gadamer: "creio que só se pode aprender através do diálogo. Esta é, certamente, uma afirmação de grande alcance, em favor da qual, eu precisaria dispor, em certo sentido, de todos os meus esforços filosóficos nos últimos decênios" (2000, p.10).

\section{Conclusão}

A grande contribuição da hermenêutica filosófica é a possibilidade que ela tem de nos permitir pensar um outro pensar. Esse pensar que pensa o outro pensar é o próprio ato do pensamento que pensa o pensamento. Parece-nos estranho e redundante ter que pensar o pensar, mas não é um ato ignóbil e obscuro conceber o pensamento do pensamento, ao contrário, é olharmos para o sentindo autêntico da nossa realidade mais particular.

Quando Heidegger anunciou em "Ser e Tempo" o esquecimento do ser, ele nos convidou para olhar para nós mesmos e a perceber no nosso "aí" que somos seres constituídos por horizontes históricos, que existimos na temporalidade.

Gadamer assume os laivos da temporalidade existencial heideggeriano e nos coloca diante da nossa atividade de percepção do mundo. Heidegger afirmou que "a linguagem é a casa do ser" e Gadamer nos mostrou que "a casa do ser" é um leque de possibilidades. Esse fenômeno, próprio da linguagem, mostra-nos que esse pensamento do pensamento se desenvolve em uma epistemologia da compreensão que começa na pré-compreensão. O "pré-compreender" estabelece um critério do entendimento que não se orienta pela tecnicidade.

O técnico é apenas uma das diversas formas do fenômeno do entendimento e da compreensão. Essa experiência que nos mostra que 
somos seres constituídos por um prognóstico temporal e espacial, prova-nos que o pensamento é possível fora da "cabeça", de modo, que na proposta de uma hermenêutica filosófica, situamo-nos no problema fundamental da nossa existência.

Pensar a existência implica pensar que a gênese do pensamento grego não sucumbiu com o declínio das cidades estados da Grécia antiga, mas que os problemas dos gregos continuam sendo os problemas da nossa existência, nesse exato momento do tempo e do espaço, nessa vastidão cósmica que escapa à nossa capacidade de compreender toda a totalidade, e na verdade, não apenas a totalidade do mundo, mas a incapacidade de compreender tudo o que eu sou, é sem dúvida, a possibilidade de ressignificação daquilo que entendemos como ciência e humanidades.

O fenômeno da compreensão na cultura ocidental só é possível por meio de um projeto inaugurado na "Paidéia" grega, que é a tentativa de formar ${ }^{6}$ o homem em uma práxis educativa. É nesse sentido, que o presente trabalho assume elucidativamente o processo educativo clássico como sendo uma centelha para pensar os processos educativos contemporâneos. A emblemática experiência da obra de arte conclamada em "Verdade e Método" por Gadamer, mostra-nos o desvelamento de uma vivência que se estabelece no diálogo. A hermenêutica filosófica, por ser um outro pensar,

\footnotetext{
${ }^{6} \mathrm{O}$ conceito de "formar" posto na ótica de Gadamer nos aproxima de um ato de "Formação" que não exclui os processos educativos. O termo alemão "Bildung", em que "Bild" traduz-se como "forma", dilucidamento daquilo que o intelecto traz para si no processo de compreensão, comumente posto na tradição como "imagem", o que complementa o prefixo "ung" como sendo não apenas uma "forma", mas uma "formação", mostra-nos em que sentido pensamos o ato formativo dos processos educativos (BERMAN, 1984). Entre a "forma" e a "formação", temos um procedimento pedagógico. Nesse sentido, não é nossa intenção explorar o conceito de "formar" tendo em vista seu caráter de amplitude, tão comum à filosofia moderna alemão, que nos põe desde Kant até o romantismo alemão, mas de nos lançarmos, paulatinamente, em um horizonte histórico de significado ligado ao dinamismo humano perante o seu "aí" na mundanidade. Não assumimos o ato de "formar" dentro do caráter técnico científico, que visualiza um problema e o analisa em uma perspectiva de correntes de pensamento, mas de um ato hermenêutico. Em tese, nossa ideia é a de mostrar que os processos educativos é um acontecimento da existência do homem no próprio mundo, exigência que mostramos sutilmente diante do olhar aos problemas originários vindo das investidas gregas sobre o tema posto em nossa breve investigação.
} 
convida-nos a um pensamento educativo que expresse o fenômeno epistêmico na atitude dialógica ${ }^{7}$.

Quando falamos em educar dialogicamente tentamos evidenciar a necessidade de capacitar os estudantes para desafios futuros, afastando-os da vertente de uma educação reprodutivista, que os prepara tão somente para a memorização de conceitos e não os sedimenta para a realidade da vida pessoal e profisisional.

Acreditamos ser possível, por meio dessa dialogicidade, o desenvolvimento de um processo no qual a educação se torne um caminho de conscientização e desenvolvimento de senso crítico, onde a sala de aula deixe de ser mero espaço de repetição de conteúdos e passe a ser um centro de desenvolvimento humano nas mais diversas vertentes.

Essa atitude se torna urgente em nossa época, em especial na forma como pretendemos educar a nós mesmos e as próximas gerações. Deixamos nas linhas dessa breve reflexão, um convite, para pensar a educação nos moldes de uma hermenêutica filosófica, que nos coloca diante de uma realidade improtelável para pensar a formação humanista nessa mixórdia em

\footnotetext{
${ }^{7}$ Trata-se de aplicar o círculo hermenêutico numa performance educativa. O diálogo hermenêutico de Gadamer discorre criticamente sobre o método científico, que durante o processo moderno adentrou em diversas correntes pedagógicas. Para o autor de "Verdade e Método", essa radicalização dos dispositivos científicos como meios "sublimes" de compreensão da realidade não é compatível com à essência do pensamento filosófico. Certamente, essa herança de Gadamer é um fulcro vindo da filosofia de Heidegger, em especial na ideia que demarca filosofia e ciência, não no sentido de desmerecer uma em detrimento da outra, mas de considerar os elementos "ônticos" existenciais como fundamentais na análise da totalidade. Temos nessa circunspeção criticista, um problema que não se restringe apenas ao problema metodológico, mas ao problema que perpassa investidas gnosiológicas, que têm como fundamentação o rigor objetivo da ciência. Não concebemos em nossa análise a ciência como único reduto explicativo da realidade, e, consequentemente, padrão normativo para as ciências pedagógicas. Todavia, como assumir essa perspectiva sem cair no reducionismo teórico? Por meio do "dialógico", compreendido em nosso artigo como expansão de possibilidades, em especial daquilo que concerne à temporalidade e espacialidade, como no exemplo gademriano da experiência com a obra de arte: a obra de arte não leva em consideração apenas o advento da técnica e da forma, mas o da vivência do ser do ente no próprio mundo. O diálogo na educação não é visto em nossa proposta tão somente como uma espécie de pedagogia de "reciprocidade", tampouco desconsideramos os métodos científicos. Mas, não podemos deixar de elencar que no "dialógico" encontramos elementos de uma filosofia geral da realidade, a saber, os processos existenciais que circundam a atividade do homem perante a educação. Tratase de uma proposta de reestruturação do pensamento ante o próprio ato de pensar, um diálogo que os leva a uma espécie de meta-pedagogia, o que significa uma pedagogia da pedagogia. Essa "pedagogia", só é possível na ótica de Gadamer, se, em sua estrutura, estiver presente uma hermenêutica do diálogo.
} 
que se encontra o mundo contemporâneo. Por isso, encerremos nossa centelha investigativa com a emblemática passagem da "Kant und das problem der metaphysik" (Kant e o problema da metafísica) de Martin Heidegger:

Nenhuma época soube tanto e de maneira tão diversa a respeito do homem como a atual. Nenhuma época expôs o conhecimento acerca do homem de maneira mais penetrante nem mais fascinante como a atual. Nenhuma época, até o momento, tem sido capaz de fazer acessível este saber com a rapidez e a facilidade como a atual. E, no entanto, nenhuma época soube menos acerca do que o homem é. Nenhuma época fez com que o homem se tornasse tão problemático como a nossa (1973, p. 203).

\section{REFERÊNCIAS}

BERMAN, Antoine. Bildung et Bildungsroman. Le temps de la réflexion, v. 4, Paris, 1984.

COSTA, Leandro Sousa. Filosofia Hermenêutica. Curitiba:InterSaberes, 2017.

DEL POZO, Rosario García. Michel Foucault:Un Arqueólogo del Humanismo. Sevilla: Universidad de Sevilla, 1988.

FLICKINGER, Hans- Georg. Gadamer\&aeducação. Belo Horizonte: Autêntica, 2014.

GEUSS, R., Kultur, Bildung, Geist in History and Theory, Vol. 35, No. 2, 1996.

GADAMER, H-G. Verdade e método: traços fundamentais de uma hermenêtitica filosófica. 3.ed. Petropólis: Vozes, 1999.

GADAMER, H-G. Homem e linguagem. In: ALMEIDA, C.L; FLICKINGER, H.G; ROHDEN, L. Hermenêutica filosófica: nas trilhas de HansGeorg Gadamer. Porto Alegre: EDIPUCRS, 2000b.

GADAMER, Hans-Georg.La educación es educarse. Trad. Francesc PereñaBlasi. Barcelona: Paidós, 2000.

Filos. e Educ., Campinas, SP, v.10, n.2, p.379-405, maio/ago. 2018 - ISSN 1984-9605 
GHIRALDELLI, Paulo Jr. Filosofia da Educação. São Paulo: Ática, 2006.

GRONDIN, Jean. Hermenêutica. São Paulo: Parábola Editorial, 2012.

HEIDEGGER, M. O ser e o tempo.Petrópoles: Vozes, 1986.

HEIDEGGER, M. Kant und das problem der metaphysik. Tradução nossa. Frankfurt: Vittorio Klostermann, 1973

JAEGER, Werner Wilhelm.Paideia: a formação do homem grego. São Paulo: WMF Martins Fontes, 2013.

LINDBERG, David. Science and the early Christian church.ISIS, v.74. 1983.

MORANDI, Franc. Introdução à Pedagogia. São Paulo: Ática, 2008.

PLATÃO. O banquete. Porto Alegre:L\&PM,2004.

REBOUL, Oliver. Quando seu filho amanhã te perguntar.[S.1]: 1971.

REICHENBACH, Hans. La nascita della filosofia scientifica. Bolonha. 1961.

SCHMIDT, Lawrence K. Hermenêutica. 3.ed. Petrópolis: Vozes, 2014.

SCHURÉ, E. OS Grandes Iniciados (Hermes)1.ed. São Paulo: Martin Claret, 1986.

Submetido em: $12 / 05 / 2018$

Aceito em: 02/10/2018

Publicado em: 15/10/2018

Filos. e Educ., Campinas, SP, v.10, n.2, p.379-405, maio/ago. 2018 - ISSN 1984-9605 